\title{
Effect of reducing agent species on reduction and slag-metal separation from carbon composite pellets
}

\author{
Shihan Zhang ${ }^{1, a}$, Guang Wang ${ }^{2, \mathrm{b*}}$, Jingsong Wang ${ }^{3, \mathrm{c}}$ and Buxin $\mathrm{Su}^{4}$ \\ ${ }^{1}$ State Key Laboratory of Advanced Metallurgy, University of Science and Technology Beijing, \\ Beijing 100083, China. \\ ${ }^{2}$ State Key Laboratory of Advanced Metallurgy, University of Science and Technology Beijing, \\ Beijing 100083, China \\ ${ }^{3}$ State Key Laboratory of Advanced Metallurgy, University of Science and Technology Beijing, \\ Beijing 100083, China. \\ ${ }^{4}$ China Metallurgical Industry Planning and Research Institute, \\ Beijing 100083, China. \\ ${ }^{a} E-m a i l:$ swlovezsh@sina.cn, ${ }^{b} E-m a i l:$ wangguang@ustb.edu.cn, \\ 'E-mail: wangjingsong@ustb.edu.cn
}

Keywords: reducing agent, carbon composite pellet, reduction and melting separation

Abstract. The rotary hearth furnace iron nugget process has advantages of short reaction time and high quality product. Using semi-coke, bituminous coal, anthracite, charcoal and coke as raw material, effects of reducing agent species on reduction and melting separation of carbon composite pellets were studied. Results showed that reducing agent species had a great influence on reduction and melting separation behaviors of carbon composite pellets. Bituminous coal as the reducing agent could lead to the best reducing effect, but it played a negative role in slag-metal separation. For comprehensive consideration of economic benefits, melting separated quality and energy consumption, optimum reducing agent was semi-coke. Optimum reduction temperature and melting separated temperature was $1200^{\circ} \mathrm{C}$ and $1375^{\circ} \mathrm{C}$ respectively. Under this condition, the recovery rate of metallic iron could reach $92 \%$.

\section{Introduction}

Compared with traditional blast furnace process, the rotary hearth furnace iron nugget process has advantages of short process, raw material flexibility, short reduction times and high quality iron nugget and has strong competitiveness in energy, cost, environmental protection, material adaptability and so on. So the rotary hearth furnace iron nugget process has vital significance to the ecofriendly development of iron and steel industry ${ }^{[1-3]}$.

Reducing agent is an important part of iron ore carbon composite pellets and the properties of reducing agent have an important influence on reduction and melting separated behaviors. Therefore, the present work studied the effects of reducing agent species on reduction and melting separated behaviors of carbon composite pellets by pre-reduction and melting separation experiment. And optimum reference for selection and evaluation of carbonaceous reducing agent used in rotary hearth furnace iron nugget process was obtained.

${ }^{*}$ Corresponding author: Email: E-mail: wangguang@ ustb.edu.cn 


\section{Experimental}

\section{Raw materials}

The chemical composition of the iron concentrate used in this study is shown in Table 1 . The iron grade was $60 \mathrm{wt} \%$ and $98 \mathrm{wt} \%$ of the iron ore concentrate particles was smaller than $0.074 \mathrm{~mm}$. The proximate analysis and ash fusibility of different species of reducing agents used in this study are shown in Table 2 . All reducing agent particles passed $0.048 \mathrm{~mm}$ opening sieve.

Table1. Chemical composition of iron concentrate [wt \% ]

\begin{tabular}{ccccccccc}
\hline $\mathrm{TFe}$ & $\mathrm{FeO}$ & $\mathrm{SiO}_{2}$ & $\mathrm{Al}_{2} \mathrm{O}_{3}$ & $\mathrm{CaO}$ & $\mathrm{MgO}$ & $\mathrm{MnO}$ & $\mathrm{P}$ & $\mathrm{S}$ \\
\hline 60 & 27.2 & 13.8 & 0.75 & 0.16 & 0.54 & 0.04 & 0.022 & 0.19 \\
\hline
\end{tabular}

Table2. Proximate analysis and ash fusibility of reducing agents

\begin{tabular}{|c|c|c|c|c|c|c|c|c|}
\hline \multirow{2}{*}{ Species } & \multicolumn{4}{|c|}{ Proximate analysis[wt \% ] } & \multicolumn{4}{|c|}{ Ash fusibility $\left[{ }^{\circ} \mathrm{C}\right]$} \\
\hline & $\mathrm{FC}_{\mathrm{d}}$ & $\mathrm{V}_{\mathrm{d}}$ & $\mathrm{A}_{\mathrm{d}}$ & $S$ & DT & ST & HT & FT \\
\hline Semi-coke & 70.77 & 8.81 & 20.42 & 0.15 & 1200 & 1210 & 1220 & 1230 \\
\hline Bituminous coal1 & 74.84 & 12.57 & 12.59 & 0.21 & 1180 & 1250 & 1280 & 1340 \\
\hline Bituminous coal2 & 71.86 & 16.52 & 11.62 & 0.61 & 1280 & $>1500$ & - & - \\
\hline Bituminous coal3 & 71.53 & 13.32 & 15.15 & 0.90 & 1350 & $>1500$ & - & - \\
\hline Anthracite & 81.40 & 6.40 & 12.20 & 0.34 & 1300 & 1320 & 1350 & 1380 \\
\hline Charcoal & 58.81 & 37.53 & 3.66 & 0.05 & 1395 & 1500 & $>1500$ & - \\
\hline Coke1 & 86.20 & 1.64 & 12.16 & 0.69 & 1460 & $>1500$ & - & - \\
\hline Coke2 & 85.73 & 1.87 & 12.40 & 0.67 & 1400 & $>1500$ & - & - \\
\hline
\end{tabular}

Note: FCd represents the fixed carbon (dry basis), $V_{d}$ the volatile matter (dry basis), $A_{d}$ the ash (dry basis), $S$ the total sulfur, DT the deformation temperature, ST the softening temperature, HT the hemispherical temperature, and FT the following temperature

Experimental procedure

The iron concentrate and reducing agentwere fully mixed. The mole ratio between the fixed carbon in the reducing agent and the oxygen of iron oxides in the concentrate was 1.2. Slag basicity was 0.8 after the addition of $\mathrm{CaCO}_{3}$ and $\mathrm{Al}_{2} \mathrm{O}_{3}$ content of iron concentrate was $6 \mathrm{wt} \%$ after the addition of $\mathrm{Al}_{2} \mathrm{O}_{3}$. The moisture content of the mixture was controlled at $7 \mathrm{wt} \%$, and the mixture was again fully mixed. The pelletizing process was performed through a manual ball press under a pressure of $20 \mathrm{MPa}$. The size of the columnar pellet was $\varphi 20.0 \times 11 \mathrm{~mm}$. The weight of each green pellet was $10 \mathrm{~g}$. Green pellets were dried at a temperature of $110^{\circ} \mathrm{C}$ for $2 \mathrm{~h}$ before the reduction experiment. Pellets were reduced using a vertical tube furnace from $1000^{\circ} \mathrm{C}$ to $1200^{\circ} \mathrm{C}$. High purity Ar was supplied to control the atmosphere in the furnace. Each sample was held at the target temperature in the furnace for over 30min to ensure completion of reactions. The melting separation was performed in closed MoSi2 box resistance furnace. The melting separated temperature was selected at 1350 and $1375^{\circ} \mathrm{C}$ respectively. Metallization pellets and separated slag were ground into powder for chemical analysis. The mass fraction of iron and metallic iron of separated slag was obtained. Then the metallization rate and recovery rate of metallic iron of pellets were calculated.

\section{Results and discussion}

Fig.1 shows the effect of reducing agent species on metallization rate of reduced pellets. As 
evident in the figure, at $1000^{\circ} \mathrm{C}$, the metallization rate of bituminous coal pellets was the highest and above $85 \%$. The metallization rate of anthracite pellets, charcoal pellets and coke pellets was relatively close and about $83 \%$, slightly lower than that of bituminous coal pellets. The metallization rate of semi-coke pellets was the lowest and only $76.17 \%$. At $1100{ }^{\circ} \mathrm{C}$, the metallization rate of different species of reducing agent pellets increased significantly with the increase of temperature. The metallization rate of charcoal pellets and semi-coke pellets was relative low and $80.46 \%$ and $85.05 \%$ respectively. The metallization rate of other reducing agent pellets was about $90 \%$. At $1200^{\circ} \mathrm{C}$, the metallization rate of semi-coke pellets was still low and the metallization rate of other reducing agent pellets was about $92 \%$. The ash fusion point of semi-coke was the lowest among eight species of carbonaceous reducing agent. Rapid melting of ash led to insufficiency of reduction of pellets and lower metallization rate of semi-coke pellets. The reactivity of charcoal was higher and the gasification rate of carbon was faster in the process of reduction, which caused lower utilization of $\mathrm{CO}$ and lower metallization rate of charcoal pellets at low temperature. At $1200^{\circ} \mathrm{C}$, the utilization of $\mathrm{CO}$ and reduction efficiency of volatiles significantly improved, which caused the increase of metallization rate of charcoal pellets. In summary, when selected bituminous coal as reducing agent, high metallization rate could be achieved at relative low temperature and optimum reduction temperature was $1200^{\circ} \mathrm{C}$.

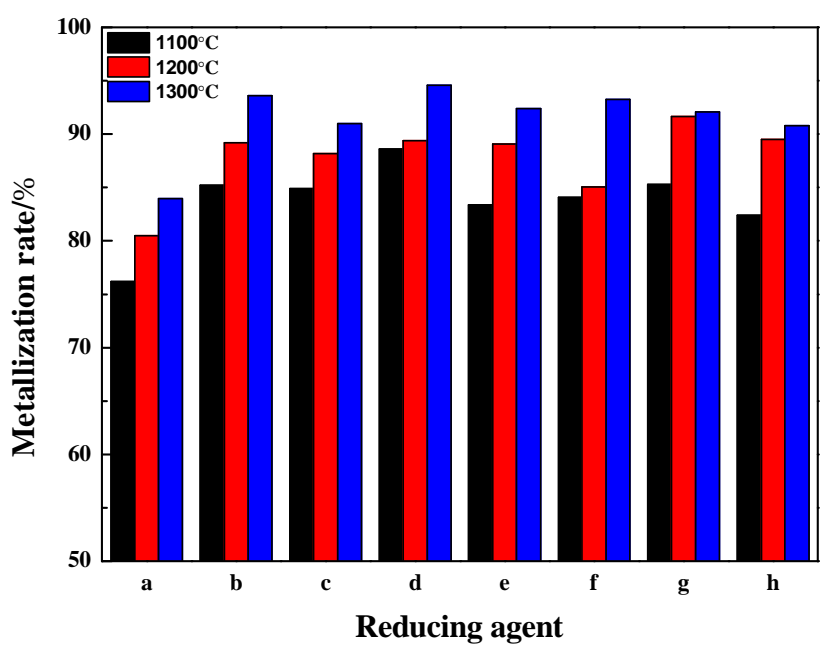

Fig1. Effect of reducing agent species on metallization rate $(30 \mathrm{~min})$

(a-Semi-coke, b-Bituminous coal1, c- Bituminous coal2, d- Bituminous coal3, e-Anthracite, f-Charcoal, g-Coke1, h- Coke2)

Effect of reducing agent species on morphology of melting separated product of pre-reduced pellets is shown in Fig. 2. As evident in the figure, at $1350^{\circ} \mathrm{C}$, semi-coke pellets and anthracite pellets could realize complete slag-metal separation and other reducing agent pellets could not realize slag-metal separation. At $1375^{\circ} \mathrm{C}$, the melting separated quality of bituminous coal 3 pellets was poor and the rest of reducing agent pellets could realize complete slag-metal separation. The ash fusion point of semi-coke and anthracite was $1220^{\circ} \mathrm{C}$ and $1350^{\circ} \mathrm{C}$ respectively, which was lower than the melting separation temperature. Rapid melting of ash could promote slag formation and carburization of metallic iron, which was beneficial to melting separation of pellets. Although the ash fusion point of bituminous coal1 was also lower than $1350^{\circ} \mathrm{C}$, bituminous coal1 pellets could not realize slag-metal separation. The volatiles of bituminous coall were higher than anthracite. The removal of volatiles was fast at early period of reduction process, which made the formation of void in pellet easier. The contact between carbon and the metallic iron particles was 
worse, which hindered the carburization of metallic iron and the melting separation of bituminous coall pellets. The recovery rate of metallic iron of semi-coke pellets and anthracite pellets was relatively close and about $92 \%$. Compared with anthracite, semi-coke has advantages of lower cost. In summary, optimum reducing agent was semi-coke and optimum melting separated temperature was $1350^{\circ} \mathrm{C}$.

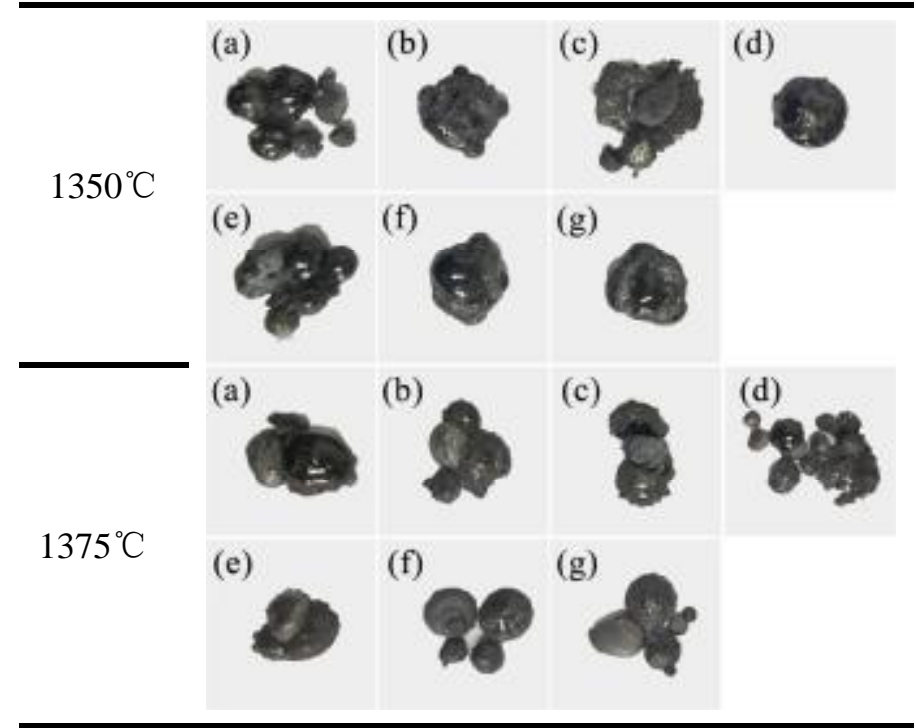

Fig2. Morphology of melting separated product of pre-reduced pellet

(a-Semi-coke, b-Bituminous coal1, c- Bituminous coal2, d- Bituminous coal3, e-Anthracite, f-Coke1, g- Coke2)

\section{Conclusions}

(1) Reducing agent species have an important influence on reduction and melting separation of pellets. Bituminous coal pellets could achieve high metallization rate at relative low temperature.

(2) For comprehensive consideration of economic benefits, melting separated quality and energy consumption, optimum reducing agent was semi-coke and optimum pre-reduced temperature and melting separated temperature was $1200^{\circ} \mathrm{C}$ and $1350^{\circ} \mathrm{C}$ respectively. Under this condition, the recovery rate of metallic iron could reach $92 \%$.

\section{Acknowledgements}

The authors would like to express their gratitude for the financial support of the China Postdoctoral Science Foundation (2016M600919), National Natural Science Foundation of China (51504216) and Fundamental Research Funds for the Central Universities (FRF-TP-16-019A1).

\section{References}

[1]I. Kobayashi, T. Yasuhiro, A. Uragami: 'A new process to produce iron directly from fine ore and coal', Iron and Steel Maker., 2001, 28:19-22.

[2]S. Kikuchi, S. Ito, I. Kobayashi: 'ITmk3 process ', Kobelco Technology Review., 2010, 29 : 77-84.

[3]G. Wang, Q.G. Xue and L.T. Kong: 'Rotary Hearth Furnace Iron Nugget Technology and Its Prospect in China', China Metallurgy., 2013, 23: 5-11. 